\title{
Análise descritiva do pai da criança com deficiência mental
}

\author{
Descriptive analysis of the father of a \\ mentally disabled child
}

\author{
Nancy Capretz Batista da SILVA \\ Ana Lúcia Rossito AIELLO'
}

\begin{abstract}
Resumo
A interação pai-criança deficiente merece atenção e precisa de mais investigações. Este estudo descreveu características dos pais de crianças com deficiência mental, com idade entre dois e quatro anos, quanto a stress, empoderamento (processo pelo qual os familiares obtêm acesso a conhecimentos, habilidades e recursos que os capacitam a ganhar controle positivo de suas vidas, bem como melhorar a qualidade de seus estilos de vida), apoio social e qualidade do ambiente. Treze pais responderam aos seguintes instrumentos: Questionário de Caracterização do Sistema Familiar, Questionário de Recursos e Stress na forma resumida, Guia Geral de Transcrição dos Dados de Entrevista, Entrevista de Caracterização do Papel do Pai na Educação da Criança com Deficiência Mental, Escala de Empoderamento da Família, Escala de Senso de Competência Parental e Observação Domiciliar para Medida do Ambiente - Primeira Infância. Os resultados indicaram pais com baixo nível socioeconômico e de escolaridade, papel tradicional, presença de stress, autoestima adequada e porcentagens elevadas de empoderamento, além de ambiente domiciliar pobre em estimulação à criança. Os participantes se classificaram como bons pais e figuras importantes na vida das crianças, despendendo muitas horas de interação com elas. Percebe-se a necessidade de estudos com diferentes metodologias e de envolvimento do pai nos serviços profissionais para seus filhos.
\end{abstract}

Unitermos: Pai. Retardo mental. Relações pai-filho.

\begin{abstract}
The interaction between a father and his disabled child deserves attention and needs further investigation. This study described characteristics of the fathers of mentally disabled children, aged between two and fouryears old, in terms of stress, empowerment, social support and quality of the environment. Thirteen fathers answered the following tools: Characterization of Family System Questionnaire, Questionnaire on Resources and Stress - Short Form, General Guide to Transcription of Interview Data, Interview in respect of the Characterization of the Role of the Father in the Education of the Mentally Disabled Child, Family Empowerment Scale, Parent Sense of Competence Scale and Early Childhood - The Home Observation for Measurement of the Environment. Results pointed to fathers oflow socio-economic and educational levels, traditional role, presence of stress, adequate self-esteem and high percentages of empowerment, while the homeenvironment failed to stimulate the child. The participants ranked themselves as good fathers and important figures in the child's life, spending many hours interacting with the child. It can be seen that there is a need for further studies using different methodologies as well as for the father's involvement in professional services for their children.
\end{abstract}

Uniterms: Father. Mental retardation. Father-child relations.

$\boldsymbol{\nabla} \boldsymbol{\nabla} \boldsymbol{\nabla} \boldsymbol{\nabla}$

1 Universidade Federal de São Carlos, Programa de Pós-Graduação em Educação Especial. Rod. Washington Luiz, Km 235, Caixa Postal 676, 13565-905, São Carlos, SP, Brasil. Correspondência para/Correspondence to: N.C.B. SILVA. E-mail:<nancycbs@gmail.com>.

Agradecimentos: aos profissionais e as famílias das instituições pesquisadas, às contribuições dos professores do DPsi-UFSCar e à Dra. Maria Auxiliadora Dessen, aos pareceristas e ao apoio da Fundação de Amparo à Pesquisa do Estado de São Paulo. 
É possível encontrar na literatura um grande número de referências sobre a interação mãe-criança e o efeito desta sobre o desenvolvimento infantil. Entretanto, estudos mais recentes têm apontado a presença do pai biológico ou de uma figura masculina no meio familiar como um fator fundamental no desenvolvimento das crianças, em resposta às transformações ocorridas nesse meio:"O surgimento de pesquisas sobre os papéis dos homens nas famílias é resultado de várias mudanças sociais que têm influenciado os papéis tradicionais de homens e mulheres na maioria dos países" (Kassotaki, 2002, p.214), como o movimento feminista nas décadas de 1960-1970, o aumento do número de mulheres entrando na força de trabalho e de famílias monoparentais, e a redução no número de filhos em famílias nucleares. Demo (1992) acrescenta ainda a proporção elevada de nascimentos fora de um casamento, adiamento dos planos de casamento e filhos, famílias recasadas e casamentos em que o casal é provedor.

Além disso, segundo dados do Instituto Brasileiro de Geografia e Estatística (IBGE) de 1998, a quantidade de crianças que moravam em casas comandadas por um homem - sem a mulher - praticamente havia triplicado desde 1978, e o índice de pais que reivindicavama guarda dos filhos havia subido de 5,0\% para 25,0\% desde 1993 (Caruso, 2002). De 1991 a 2000 houve um aumento de $74,5 \%$ no número de homens que cuidavam sozinhos dos filhos nos domicílios brasileiros (Gois, 2002). Observa-se, desta forma, uma tendência de homens participarem cada vez mais da vida de seus filhos. Jablonski (1999) sustenta que é natural que tais mudanças sociais venham provocar novas expectativas quanto aos deveres dos homens como pais e quanto a novos padrões atitudinais e comportamentais. Por isso, é importante conhecer a importância do pai, como ele contribui e participa no desenvolvimento dos filhos e no funcionamento familiar.

Em seu estudo sobre família e socialização, Baruffi (2000) propõe que o pai e a mãe possuem tarefas específicas e primordiais no processo de desenvolvimento do indivíduo em direção à independência. $\mathrm{O}$ pai seria uma figura importante para o desenvolvimento psicoafetivo dos filhos, indo além do papel de provedor e mantenedor da família para, por meio de seu afeto e 494 de sua atitude, ser referência na construção da perso- nalidade dos filhos e o primeiro transmissor da autoridade social: "o pai personifica autoridade e segurança, ideais e valores" (Baruffi, 2000, p.4).

Dessen e Braz (2000) apontaram a importância do pai para o funcionamento da família, já que a adaptação ao nascimento de um filho depende da complementaridade de papéis entre os genitores nas interações e nas relações familiares mais amplas, incluindo a divisão de tarefas domésticas; o pai deve suprir as deficiências naturais ocorridas no relacionamento da mãe com o filho. Em seu estudo, o papel de apoio afetivo e psicológico da família foi realizado pelas mães, enquanto os pais mantiveram sua figura associada ao papel de provedor.

Segundo Kane e Garber (2004), as interações pai-criança refletem-se nos sintomas comportamentais e emocionais das crianças. Lamb (1997), já ressaltava que crianças com pais altamente envolvidos apresentam maior competência cognitiva, maior empatia, menor crença sexualmente estereotipada e um maior nível de controle interno.

Engle e Breaux (1998) dizem que, nos Estados Unidos e na Europa, estudos mostraram que homens envolvidos com seus filhos contribuíam positivamente para o desenvolvimento intelectual, social e emocional dos mesmos. Eles exemplificam três das possíveis contribuições de um pai aos filhos: 1) construir uma relação de cuidado e envolver-se por meio de interação, disponibilidade e responsabilidade, pois há evidências de que o contato com o pai acarreta menos problemas de comportamento, mais senso de habilidade para fazer coisas e maior autoestima na criança; 2) tomar a responsabilidade econômica (melhora as condições da criança - uma vez que casas chefiadas por mães são geralmente mais pobres) e mostrar um maior compromisso (por meio da contribuição com uma porcentagem maior do seu salário para gastos com comida etc.); e 3) reduzir as chances de criar um filho fora de uma parceria com a mãe da criança (o que pode reduzir seu vínculo com a criança).

Apesar da importância do pai no desenvolvimento infantil, muitos serviços e atendimentos dirigidos à família têm a mãe e a criança como alvo, sem incluir o pai. Carvalho (2003) demonstrou que a participação dos pais em uma maternidade pareceu desvalorizada: as dificuldades encontradas "têm como pano 
de fundo a sua exclusão dos serviços de saúde reprodutiva e pediátrica, em descompasso com o crescente envolvimento dos homens na educação das crianças" (p.396). A autora propõe o fomento da discussão social sobre a paternidade e a inclusão dos homens nos programas de saúde.

Mais especificamente, Lewis e Dessen (1999) apontam para a necessidade de se conhecer as características demográficas das famílias, além do tempo e envolvimento dos pais com suas crianças, pois ainda que pesquisas tenham indicado o crescente envolvimento paterno e as mudanças nos papéis que homens e mulheres exercem como cuidadores em lares onde coabitam ambos os genitores, menos de $2 \%$ dos pais compartilham igualmente as tarefas de cuidados com a criança. Cubero e Moreno (1995) apontam a divisão nos papéis de pais de filhos em idade escolar, sendo que as mães interagem com seus filhos com mais frequência em contexto de cuidados, enquanto as interações com o pai ocorrem mais vezes no contexto de jogo.

Sabe-se que o papel do pai no contexto atual é muito complexo. Dessen e Lewis (1998) descrevem quatro tipos de papéis de pai: 1) o pai biológico; 2) alguém que provêa subsistência da criança (pai econômico);3) um homem (ou homens) que a criança identifica como uma figura de pai (pai social); e 4) alguém que é legalmente identificado como um pai. Um homem pode desempenhar todos esses papéis, embora cada um possa ser desempenhado por diferentes homens. Os papéis que os pais têm adotado podem ser vistos, também, em uma perspectiva cultural e histórica, como: 1) tradicional - no qual as atividades primárias centramse no trabalho, fazendo-se pouco em relação às atividades de cuidado das crianças; 2) moderno - pais que veem o desenvolvimento bem sucedido da criança como um objetivo importante, especialmente nas áreas de desenvolvimento da identidade do papel sexual, desempenho acadêmico e desenvolvimento moral (ou emergente); estes participam mais igualmente com suas esposas das atividades de cuidados com a criança (Dessen \& Lewis, 1998).

Já nas famílias de crianças com deficiência mental, o que se sabe sobre o papel do pai é muito pouco. Os estudos sobre o desenvolvimento dessas crianças ficam centrados na mãe e nas informações dadas por esta, deixando a figura paterna em segundo plano (Glat, 1996) e, mesmo quando incluem o pai, seu ponto de vista não é estudado (Omote, 1998). Pereira-Silva e Dessen (2003), em estudo sobre crianças com Síndrome de Down e suas interações familiares, concluíram que é de extrema importância a implementação de pesquisas que incluam o pai dessas crianças.

Omote (1996) aponta que os familiares devem ser envolvidos na compreensão das dificuldades e limitações do deficiente e na tarefa de educá-lo. Além disso, eles "apresentam necessidades especiais de atendimento, decorrentes da sua condição de ser mãe, pai, irmão ou irmã de um indivíduo reconhecido e tratado como deficiente" (p.516). Assim, Canho, Neme e Yamada (2006) apontam a necessidade crescente de se compreender a participação do pai nas relações e tarefas familiares, especialmente relacionadas à educação e reabilitação de filhos com necessidades especiais.

Segundo Lamb e Billings (1997), nos últimos vinte anos, muita atenção foi dada ao impacto de uma criança com necessidades especiais no ajuste e satisfação marital de seus pais na perspectiva da mãe. Como resultado, ainda não se sabe quanto e como os pais - homens - gastam seu tempo com suas crianças que têm o desenvolvimento comprometido, ou como seus pensamentos e relações são afetados pelas inabilidades de seus filhos. Assim, outros aspectos importantes em relação à participação e envolvimento paterno na família com crianças especiais não têm sido investigados e, quando investigados, ainda têm sido pouco explorados, e as descobertas têm sido variadas.

De acordo com Bailey, Blasco e Simeonsson (1992), pesquisas têm focado a extensão com a qual o nascimento de uma criança com deficiência causa impacto no pai, a correspondência entre as respostas paternas a esse impacto comparadas às relatadas pelas mães e em que extensão os pais (homens) são envolvidos com suas crianças ou com serviços oferecidos à criança. Às vezes, relata-se que as mães são significativamente mais envolvidas que os pais e, outras vezes, que os pais gastam um tempo significativo com seus filhos deficientes.

Devido às descobertas incongruentes, à falta de pesquisas caracterizando os pais brasileiros de crianças com deficiência mental e ao pouco conhecimento sobre o papel que os pais atuais desempenham na educação 
de seus filhos com necessidades especiais, o estudo aqui descrito visou descrever características de pais de crianças com deficiência mental. Pretendeu-se contribuir para o melhor entendimento do contexto ambiental dessas crianças, com o intuito de favorecer o atendimento oferecido a elas e aos seus cuidadores. Visou-se fornecer parâmetros para uma compreensão da contribuição do homem na família e sua visão sobre sua condição de paternidade.

\section{Método}

\section{Participantes}

Participaram do estudo 13 homens, residentes em uma cidade de porte médio (seis pais) e outra de grande porte (sete pais) do interior paulista. A seleção dos pais obedeceu aos seguintes critérios: ter filhos com deficiência mental estudando em escolas especiais públicas na faixa etária de dois a quatro anos; ser o pai biológico; coabitar com a criança. Entre todos os pais encontrados que atendiam aos critérios, cinco não aceitaram ou não puderam participar do estudo.

\section{Instrumentos}

Foram utilizados os seguintes instrumentos: versões traduzidas do Inventário Early Childhood - The Home Observation for Measurement of the Environment (EC-HOME) (Caldwell \& Bradley, 2001), do Questionário de Recursos e Stress na forma resumida (QRS-F) (Friedrich, Greenberg e Crnic, 1983), da Escala de Senso de Competência Parental (PSOC) (Johnston \& Mash, 1989), da Escala de Empoderamento da Família (FES) (Koren, De Chillo \& Friesen, 1992), uma versão adaptada das partes C e D do Guia Geral de Transcrição dos Dados de Entrevista (Dessen, 2002a), o Questionário de Caracterização do Sistema Familiar (Dessen, 2002b) e um roteiro de Entrevista de Caracterização do Papel do Pai Brasileiro na Educação da Criança com Deficiência Mental, para uma descrição mais completa de variáveis descritas pela literatura como impactantes no papel desempenhado pelo pai ou como importantes para programar intervenções (Andrews, Luckey, Bolden, Whiting-Fickling \& Lind, 2004; Dessen, 1985; Guille, 2004; Levandowski \& Piccinini, 2002; Sigolo, 2004; Williams \&

496 Aiello, 2004).
Tais instrumentos foram utilizados visando descrever a qualidade e a quantidade de estimulação e apoio disponível para o filho no ambiente domiciliar, o impacto da criança com atraso de desenvolvimento ou cronicamente doente nos outros membros da família, a autoestima do pai, o nível de empoderamento da família (processo pelo qual os familiares obtêm acesso a conhecimentos, habilidades e recursos que os capacitam a ganhar controle positivo de suas vidas, bem como melhorar a qualidade de seus estilos de vida) e informações sobre as características demográficas da família (idade, escolaridade, renda), do sistema familiar (divisão do trabalho doméstico e experiências de vida) e da rede social de apoio no nascimento da criança.

As partes C e D do Guia Geral de Transcrição dos Dados de Entrevista (Dessen, 2002a) investigaram a participação e apoio dispensados pelo pai em relação às tarefas domésticas e aos cuidados com os filhos, sentimentos e expectativas quanto à participação do pai na vida familiar e influência dos avós na vida familiar. O roteiro de Entrevista de Caracterização do Papel do Pai Brasileiro na Educação da Criança com Deficiência Mental levantou informações sobre o relacionamento pai/filho, percepções sobre a paternidade, sentimentos e expectativas quanto à participação na vida familiar e como seus pensamentos e relações são afetados pelas inabilidades de seus filhos. Também foram utilizados gravador e fitas cassetes para gravar as entrevistas, autorização das instituições de ensino e um termo de consentimento livre e esclarecido para os pais, que também assinaram uma autorização para gravações.

\section{Procedimentos}

Após aprovação do Comitê de Ética em Pesquisa para Experimentos em Seres Humanos da Universidade Federal de São Carlos (protocolo 033/03) e das instituições envolvidas, as anamneses e prontuários foram consultados, a fim de selecionar as crianças e os pais que obedeciam aos critérios de seleção pré-estabelecidos; estes pais foram contatados, em seguida, para explicação dos métodos e objetivos e obtenção do consentimento livre e esclarecido. O estudo foi realizado na casa do pai e nos locais mais convenientes para ele, como seu local de trabalho, a escola da criança ou a própria universidade. 
O primeiro encontro foi realizado na residência da família, com a aplicação do Questionário de Caracterização do Sistema Familiar. Em seguida, foram aplicados os demais instrumentos em várias visitas de, aproximadamente, uma hora. A pesquisadora fazia as questões e anotava as respostas, em razão da dificuldade de leitura e compreensão de alguns pais. Nessas ocasiões, a pesquisadora limitou-se a repetir a questão ou usar palavras mais simples, sem direcionar a resposta do pai. Os pais responderam aos instrumentos em ambiente isolado para que não fossem influenciados em suas respostas, não fossem distraídos e se sentissem mais à vontade.

Com o término da aplicação dos instrumentos, foram realizadas as análises das respostas dos pais seguindo os critérios propostos pelos autores e as correlações dos resultados (FES x PSOC, QRS-F X PSOC, QRS-F $\times$ FES, FES $\times$ HOME, PSOC $\times$ HOME e QRS-F $\times$ HOME) pelo coeficiente de correlação de Pearson (nível de significância igual a 0,05). O mesmo critério foi utilizado para correlacionar esses instrumentos com a idade dos pais e o número de horas gastas com o filho, mas não houve correlação significativa. Em seguida, foi feita a correlação entre os instrumentos citados e o nível socioeconômico e de escolaridade dos pais, por comparação da média dos grupos.

\section{Resultados}

A maioria das famílias (ou seja, nove) era nuclear. A casa das famílias 7 e 13 ficava no mesmo terreno que a casa dos avós paternos; com a família 6 coabitava a irmã do pai, e com a família 12 coabitavam dois genros e três netos. O pai 12 estava em processo de separação da mãe e coabitava com a criança apenas esporadicamente.

ATabela 1 traz alguns resultados do Questionário de Caracterização do Sistema Familiar. A média da idade dos pais foi de 34 anos e 9 meses. A renda da família (considerando os auxílios, benefícios e salário da esposa somado ao do pai) foi de até mil reais para nove das treze famílias (o salário-mínimo vigente era de $\mathrm{R} \$ 260,00$ ). A família 1, cujo pai estava desempregado, não possuía renda fixa: sobrevivia de trabalhos esporádicos do pai e auxílios de vizinhos e parentes. Em termos de escolaridade, verificou-se que apenas três pais haviam comple- tado o segundo grau e somente um havia completado o terceiro grau. Os resultados dessa amostra de pais parecem indicar que eles pertenciam a uma camada social desfavorecida e com baixa escolaridade.

A média da idade das crianças foi de 43 meses. Onze delas estavam na instituição há mais de um ano e meio. Entre elas, a maioria (sete) possuía o diagnóstico de Síndrome de Down. Sete crianças participavam de terapias extracurriculares e esta participação nem sempre estava relacionada a um maior nível socioeconômico ou escolaridade mais alta dos pais, mas sim a apoios financeiros recebidos, uma vez que todas as famílias que os recebiam tinham seu filho sendo atendido em, pelo menos, uma atividade.

Quanto às mães, a média de idade foi de 32 anos e 7 meses; apenas quatro contribuíam para a renda familiar e somente quatro completaram o segundo grau. De forma geral, constatou-se que poucas mães trabaIhavam fora do lar, parecendo dedicar-se mais aos cuidados do filho e da casa.

As atividades de lazer citadas pelos pais (a maioria de baixa renda) não envolviam gastos, tais como viagens (exceto para a família 4) ou restaurantes (exceto para as famílias 7 e 12). Também se verificou que a maioria das famílias já passou por várias experiências de vida negativa: perda de emprego (famílias 1, 3, 5, 6, 7, 8, 9 e 11); hospitalização da mãe, pai ou de um filho (famílias 1, 2, 3, 4, 5, 6, 7, 8, 9, 10, 11, 12 e 13) e morte de parentes e amigos íntimos (famílias 1, 2, 3, 6, 7, 8, 9, 10, 11 e 12). Além disso, a ocorrência de impacto mais descrita pelas famílias envolvia o filho deficiente: diagnóstico da deficiência da criança (famílias 4, 6, 7, 8, 9 10, 11 e 12), acidente com mãe enquanto grávida da criança (família 5) e cirurgia da criança (família 13).

De acordo com as partes C e D do Guia Geral de Transcrição dos Dados de Entrevista, as mães realizavam a maioria das tarefas domésticas, incluindo o cuidado da criança (com exceção das famílias 4 e 11). Cinco pais $(1,2,6,9$ e 10) disseram que ajudavam nas tarefas domésticas quando a mãe solicitava ou estava ausente. Quatro pais $(3,4,8$ e 12) contaram que às vezes realizavam algumas atividades domésticas, sem mencionar pedido da mãe ou necessidade. O pai 13 raramente ou nunca fazia alguma atividade doméstica. Os pais 5, 7 e 11 enumeraram várias atividades domésticas desempenhadas frequentemente (lavar o quintal, estender 
Tabela 1. Caracterização dos participantes. São Carlos e Ribeirão Preto (SP), 2003.

\begin{tabular}{|c|c|c|c|c|c|c|c|c|c|c|c|c|c|}
\hline \multirow[b]{2}{*}{ 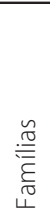 } & \multicolumn{5}{|c|}{ Pai } & \multicolumn{4}{|c|}{ Criança } & \multicolumn{4}{|c|}{ Mãe } \\
\hline & $\begin{array}{l}\text { ñ } \\
0 \\
\frac{0}{0} \\
\frac{0}{0} \\
\frac{\pi}{0}\end{array}$ & 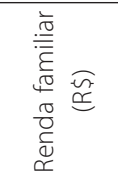 & 岀 & $\begin{array}{l}\frac{0}{0} \\
\frac{0}{0} \\
\frac{0}{0} \\
\frac{0}{0} \\
\breve{u} \\
山\end{array}$ & 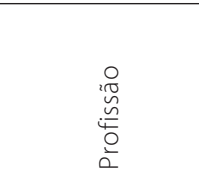 & 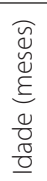 & 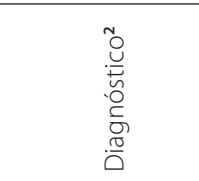 & 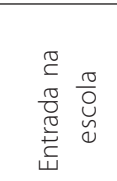 & 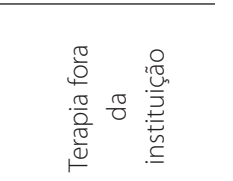 & $\begin{array}{l}\bar{n} \\
0 \\
\frac{0}{0} \\
0 \\
\frac{0}{0} \\
\frac{\pi}{0} \\
\underline{0}\end{array}$ & 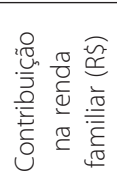 & $\begin{array}{l}\frac{0}{0} \\
\frac{\pi}{0} \\
\frac{0}{0} \\
\frac{0}{0} \\
\breve{u}\end{array}$ & 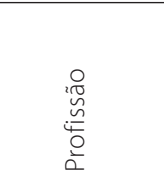 \\
\hline 1 & 32 & - & $E$ & $11^{\circ} 1$ & Desempregado & 47 & $\begin{array}{l}\text { RDNPM e } \\
\text { hiperatividade }\end{array}$ & maio/03 & - & 35 & - & $11^{\circ} 1$ & Dona de casa \\
\hline 2 & 25 & 800,00 & C & $1^{\circ} 1$ & Mecânico & 53 & $\begin{array}{l}\text { Síndrome de } \\
\text { Down }\end{array}$ & ago/99 & - & 21 & - & $1^{\circ} \mathrm{C}$ & Dona de casa \\
\hline 3 & 35 & 1500,00 & B2 & $2^{\circ} \mathrm{C}$ & $\begin{array}{l}\text { Desenhista } \\
\text { mecânico }\end{array}$ & 51 & $\begin{array}{l}\text { Hidrocefalia e } \\
\text { autismo }\end{array}$ & set/01 & $\begin{array}{l}\text { Fisio/hidroterapia; } \\
\text { fonoaudiologia }\end{array}$ & 32 & - & $2^{\circ} \mathrm{C}$ & Dona de casa \\
\hline 4 & 30 & 6300,00 & $\mathrm{~A} 1$ & $3^{\circ} \mathrm{C}$ & $\begin{array}{l}\text { Professor } \\
\text { universitário }\end{array}$ & 43 & $\begin{array}{l}\text { Síndrome de } \\
\text { Down }\end{array}$ & set/99 & $\begin{array}{l}\text { Terapia } \\
\text { ocupacional }\end{array}$ & 39 & 2300,00 & $3^{\circ} \mathrm{C}$ & $\begin{array}{l}\text { Professora } \\
\text { universitária }\end{array}$ \\
\hline 5 & 32 & $790,00^{3}$ & C & $1^{\circ} 1$ & Garçom & 52 & RDNPM & out/01 & Fisioterapia & 40 & - & $1^{\circ} 1$ & Dona de casa \\
\hline 6 & 51 & $290,00^{4}$ & D & $1^{\circ} 1$ & Desempregado & 53 & $\begin{array}{l}\text { Síndrome de } \\
\text { Down }\end{array}$ & maio/00 & Natação & 36 & - & $1^{\circ} 1$ & Dona de casa \\
\hline 7 & 26 & 550,00 & C & $1^{\circ} 1$ & Pedreiro & 53 & $\begin{array}{l}\text { Atraso de } \\
\text { desenvolviment }\end{array}$ & $\begin{array}{l}\text { ago/01 } \\
0\end{array}$ & - & 29 & - & $1^{\circ} 1$ & Dona de casa \\
\hline 8 & 26 & $640,00^{3}$ & C & $1^{\circ} 1$ & Vendedor & 31 & $\begin{array}{l}\text { Síndrome de } \\
\text { Down }\end{array}$ & $\mathrm{fev} / 01$ & $\begin{array}{l}\text { Fonaudiologia; } \\
\text { musicoterapia }\end{array}$ & 27 & - & $2^{\circ} \mathrm{C}$ & Dona de casa \\
\hline 9 & 40 & 750,00 & C & $2^{\circ} \mathrm{C}$ & Entregador & 35 & $\begin{array}{l}\text { Síndrome de } \\
\text { Down }\end{array}$ & jul/00 & - & 34 & 50,00 & $2^{\circ} \mathrm{C}$ & Manicure \\
\hline 10 & 37 & 900,00 & C & $1^{\circ} 1$ & $\begin{array}{l}\text { Auxiliar de } \\
\text { produção }\end{array}$ & 36 & RDNPM & $\mathrm{jul} / 00$ & - & 33 & 300,00 & $1^{\circ} 1$ & Diarista \\
\hline 11 & 66 & $780,00^{3}$ & C & $1^{\circ} 1$ & Aposentado & 37 & $\begin{array}{l}\text { Atraso } \\
\text { pós-acidente }\end{array}$ & jan/03 & Hidroterapia & 31 & - & $1^{\circ} 1$ & Dona de casa \\
\hline 12 & 27 & 1980,00 & B1 & $1^{\circ} \mathrm{C}$ & Frentista & 33 & $\begin{array}{l}\text { Síndrome de } \\
\text { Down }\end{array}$ & fev/01 & - & 44 & 1500,00 & $2^{\circ} 1$ & Pensionista \\
\hline 13 & 26 & $700,00^{5}$ & C & $2^{\circ} \mathrm{C}$ & Balconista & 32 & $\begin{array}{l}\text { Síndrome de } \\
\text { Down }\end{array}$ & maio/00 & Equoterapia & 24 & - & $2^{\circ} 1$ & Dona de casa \\
\hline
\end{tabular}

I: incompleto; C: completo; RDNPM: retardo de desenvolvimento neuropsicomotor.

${ }^{1}$ CSE: Classificação socioeconômica considerando renda da mãe. Fonte: <http://www.ibope.com.br/social/produtos/aspprc20.htm>.

2 Obtido no prontuário da criança, disponível na instituição de ensino.

${ }^{3} \mathrm{R} \$ 240,00$ referente a benefício da criança

${ }^{4} \mathrm{R} \$ 240,00$ referente a benefício da criança e $\mathrm{R} \$ 50,00$ do programa federal "Fome Zero".

${ }^{5} \mathrm{R} \$ 120,00$ referente a bônus salarial para a criança.

roupas no varal, cozinhar, lavar a louça, lavar o banheiro, lavar a roupa, varrer a casa e limpar os móveis). Quando

os pais se responsabilizavam pelo cuidado da criança, suas atividades eram: dar banho, trocar a fralda, dar mamadeira, pôr para dormir, cortar as unhas, dar remédio, pentear os cabelos e dar comida. Os pais 3, 7 e 13 disseram que sempre se responsabilizavam por alguns desses cuidados. Algumas atividades que os pais 3, 4, 5, 6 e 13 relataram realizar com a criança, que não se tratavam de itens de cuidado, foram ler e contar estórias, levar à escola, levar a alguma terapia, brincar, assistir televisão

498 ou filme junto e passear na rua.
Os pais 1, 2, 4 e 9 achavam que a participação paterna na vida familiar era a"participação ideal". Algumas justificativas dos pais foram: não sair e chegar cedo em casa (pai 1) e considerar natural que a mulher, por ficar mais em casa, assuma mais atividades domésticas (pai 4). Questionados sobre como seria uma "participação ideal", os pais responderam: "ficar mais em casa" (pais 3 e 8); "ajudar no que pode" (pais 5 e 13); "trabalhar para dar as coisas" (pais 5 e 7); "não deixar faltar as coisas" (pai 5); "ensinar coisas boas" (pai 6 e 8); "levar na escola" (pai 6); "dar amor", "ser a cabeça da casa"e "deixar as crianças mais seguras" (pai 8); "ter mais lazer com a família" (pai 
10); "dar mais conforto"e "passear mais" (pai 11); "ter mais tempo com a criança" (pai 12) e "dar educação à criança" (pai 13). É interessante notar que os pais incluíram atitudes próprias como participação ideal de um pai.

As ajudas que os avós davam, segundo os pais, eram: financeira (pais 2, 3, 9 e 13); conselhos e atenção (pais 2, 7, 8, 10 e 12); ajuda à mãe quando a criança nasceu (pais 2, 3, 7, 9, 12 e 13); procura de médicos e tratamentos e procura de bibliografias sobre o diagnóstico da criança (pai 4); suporte emocional (pais 4, 7 e 12) e cuidar da criança (pais 7 e 13).

Todos os pais mostraram algum índice indicativo de stress pela presença da criança com necessidades especiais (o instrumento permite identificar a ausência de stress), conforme medido pelo QRS-F. Contudo, onze dos treze pais apresentaram porcentagem abaixo de 50\%, revelando um índice indicativo de stress razoavelmente baixo. Os pais 7 e 10 apresentaram um índice superior (61,22\%). Os pais com menores índices indicativos de stress foram os pais $4(18,36 \%)$ e $9(20,4 \%)$.

De acordo com os dados obtidos na PSOC (Tabela 2), dez dos treze pais apresentaram porcentagem acima de 60, indicando autoestima em relação ao papel de pai um pouco acima da média do instrumento. 0 pai 11 merece destaque por sua alta pontuação (90,1\%), evidenciando uma elevada autoestima como pai. Os pais 5, 6 e 12 mostraram menor autoestima (59,8\%, 52,9\% e 57,8\%, respectivamente).

Todos os pais avaliaram-se como empoderados, como mostram os resultados da FES (Tabela 2). Oito dos treze pais apresentaram porcentagem acima de 70\%; o pai 1 obteve a maior porcentagem $(91,1 \%)$, enquanto os pais 8 e 10 apresentaram menor empoderamento (47\% e 54,7\%, respectivamente).

Quanto ao Inventário HOME (Tabela 2), 61,5\% dos pais (pais 1, 2, 3, 7, 8, 9, 10 e 11) ficaram no quarto inferior segundo a classificação do instrumento de acordo com a pontuação (até 29), indicando um ambiente domiciliar pobre em estimulação e apoio à criança. Apenas o pai 4 apresentou índices adequados (sua pontuação ficou entre 46 e 55, no quarto superior). Considerando-se que um ambiente ricamente estimulador é aquele cujo índice no HOME está acima de 46 pontos, 12 dos 13 pais (92,3\%) não preencheram este requisito, o que é preocupante.

Os pais 8 e 12 não participaram da Entrevista de Caracterização do Papel do Pai Brasileiro na Educação da Criança com Deficiência Mental por problemas pessoais. Quando receberam a notícia sobre a deficiência do filho, 90,9\% dos pais disseram terem ficado chocados. Alguns problemas causados pela presença da criança foram: limitações nas próprias realizações,

Tabela 2. Razão e porcentagem dos pais em QRS-F, PSOC, FES e HOME. São Carlos e Ribeirão Preto (SP), 2003.

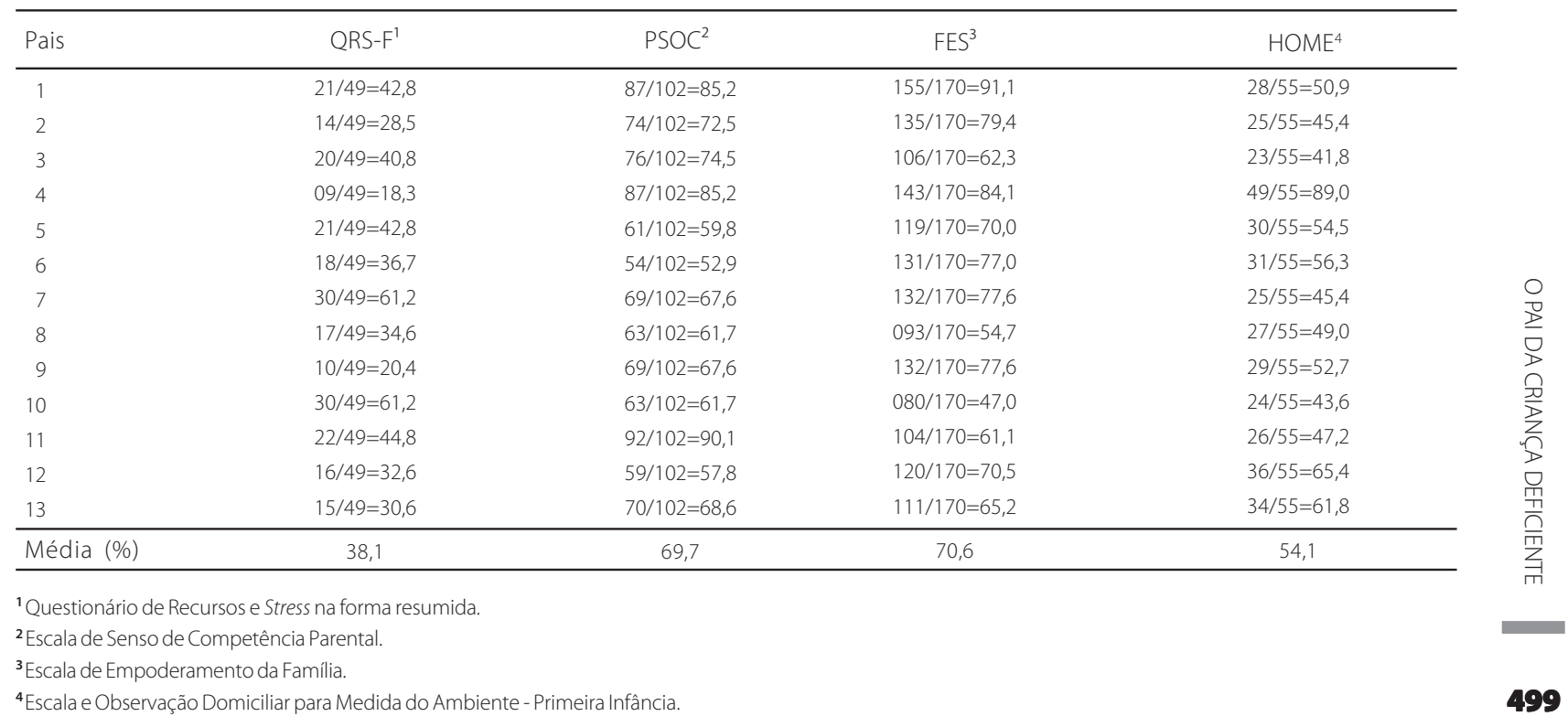


não saber se a criança estava enxergando ou ouvindo, aumento das preocupações e dúvidas quanto ao futuro. Apenas 27,3\% deles tinham contato com deficientes mentais antes do nascimento da criança e procuraram se adaptar por meio de convívio (50\%), leituras sobre o assunto (dois deles), conversas sobre o assunto (dois deles), frequentar a instituição de ensino (um pai) e participação em associação de pais com filhos com Síndrome de Down (um pai). Cabe destacar que, apesar do choque, a maioria não se engajou na procura de mais informações.

Nenhum pai se responsabilizava por decisões médicas, escolares e educacionais. Participavam apenas da escolha do médico e da aquisição de medicamentos por meio das informações trazidas pela mãe. A única decisão escolar da qual participaram foi sobre a matrícula da criança na instituição de ensino especial, realizada pela mãe, na maioria das vezes. Nenhum pai participava das decisões sobre o programa educacional oferecido pela instituição ou recebia atendimento educacional ou orientação relacionada à deficiência do filho, exceto aquele que frequentava uma associação. Assim, participavam das práticas educativas conversando com a criança quando ela fazia algo errado e explicando porque era errado e como era o correto.

Apenas para dois pais as inabilidades do filho afetavam suas relações, por causa da dificuldade de comunicação da criança para um e por serem cansativas para o outro. A maioria dos pais passava mais de seis horas por dia em casa e dizia dedicar 100\% desse tempo às crianças. Porém, dedicação para eles era a simples proximidade (ex:: "o tempo todo ele tá comigo"[sic]), e não o uso do tempo com o objetivo de dar atenção, brincar, cuidar, dar carinho e estimular o filho.

Nove dos 13 pais relataram comportamentos inadequados da criança (ex. atirar enfeites da casa), mas nenhum conhecia princípios da análise aplicada do comportamento e análise funcional, o que os levava a agir de forma inadequada (ex. reforçando comportamentos inadequados) e inconsistente (ex. ora reforçando, ora punindo o mesmo comportamento), sugerindo a necessidade de intervenções com os pais, por parte de profissionais, para melhorar suas interações e instalar comportamentos socialmente mais adequados nas crianças. Os pais citaram atitudes relacionadas à saúde $\mathbf{5 0 0}$ e estimulação da criança - brincar, oferecer espaço, estimular, matricular na instituição e conseguir cadeira de rodas, avaliações na Associação de Assistência à Criança Deficiente (AACD), cirurgia e consultas no Hospital das Clínicas - como comportamentos em prol da criança.

Dez pais se consideraram iguais aos pais sem filhos deficientes. Todos se consideraram bons pais, argumentando que tinham bom relacionamento com a família, ensinavam a ter respeito, não batiam, conversavam, davam atenção, brincavam, não deixavam passar necessidades, eram presentes, saíam juntos, ajudavam a conseguir coisas, participavam, cuidavam e auxiliavam a esposa. Também se julgaram figuras importantes para as crianças, argumentando que faziam bem a elas, acalmavam-nas, eram queridos, davam-Ihes apoio, faziam-Ihes "coisas", cuidavam, brincavam e aceitavam-nas. No futuro, todos os pais disseram que seu papel seria o de orientar e continuar buscando o melhor para o filho. Além disso, é interessante notar que sete deles relataram espontaneamente expectativas de que seus filhos seriam "normais" no futuro.

Foi encontrada uma correlação negativa moderada de -0,61678 entre HOME e QRS-F (quanto mais estressados eram os pais, pior o ambiente oferecido por eles às crianças e vice-versa). Não foi encontrada relação significativa entre os demais instrumentos. Além disso, quanto maior o nível socioeconômico menor o stress do pai, melhor é o ambiente que ele oferece à criança e mais autoestima ele apresenta. Quanto maior o nível escolar, melhor é o ambiente oferecido à criança, maior é a autoestima apresentada pelo pai e menor é o stress (Tabela 3).

Tabela 3. Correlação entre os instrumentos e o nível socioeconômico e de escolaridade dos pais por comparação da média dos grupos. São Carlos e Ribeirão Preto (SP), 2003.

\begin{tabular}{lcccc}
\hline Usuários & Grupos & Stress & Ambiente & Autoestima \\
\hline Nível & A1, B1 e B2 & 15,0 & 36,0 & 74,0 \\
Socioeconômico $^{1}$ & C & 19,8 & 27,5 & 70,1 \\
& D e E & 19,5 & 29,5 & 70,5 \\
Nível Educacional $^{2}$ & $3^{\circ} \mathrm{C}$ & 9,0 & 49,0 & 87,0 \\
& $2^{\circ} \mathrm{C}$ & 15,0 & 28,7 & 71,7 \\
& $1{ }^{\circ} \mathrm{C}$ & 16,0 & 36,0 & 59,0 \\
& $1{ }^{\circ} \mathrm{I}$ & 21,6 & 27,0 & 70,4 \\
\hline
\end{tabular}

${ }^{1}$ Classificação socioeconômica. Fonte: <http://www.ibope.com.br/ social/produtos/aspprc20.htm>.

${ }^{2}$ Primeiro, segundo e terceiro grau (níveis fundamental, médio e superior); C: Completo; I: Incompleto. 


\section{Discussão}

Este estudo procurou conhecer características demográficas, bem como o tempo e envolvimento dos pais com seus filhos, uma necessidade apontada por Lewis e Dessen (1999), enfocando o pai da criança portadora de deficiência mental. Do mesmo modo, buscou considerar o pai nas entrevistas, assim como estudar seu ponto de vista, antes omisso segundo Omote $(1996,1998)$. Procurou-se ainda saber quanto e como os homens gastam seu tempo com suas crianças que têm o desenvolvimento comprometido e como seus pensamentos e relações são afetados pelas inabilidades de seus filhos, uma lacuna apontada por Lamb e Billings (1997).

No geral, essa amostra de pais de crianças com deficiência mental na faixa etária de dois a quatro anos, de escolas especiais públicas, apresentou: 1) nível socioeconômico baixo e pouca escolaridade, fatores considerados de risco para uma paternidade favorecedora do desenvolvimento dos filhos segundo Lamb (1997); 2) pouco stress quanto à presença de um filho com deficiência mental; 3) índice indicativo de autoestima em relação ao seu papel de pai acima de $60 \%$; 4) razoável nível de empoderamento para com sua vida familiar; e 5) ambiente domiciliar pobre em estimulação para a criança. É importante lembrar que essas características podem não ser exclusivas dessa amostra de pais de crianças deficientes mentais, sendo necessários mais estudos nessa área.

Nessas famílias, 69,2\% das mães não estavam no mercado de trabalho, muitos casais tinham outros filhos, todas as famílias eram consanguíneas e apenas dois homens ficavam em casa. Futuros estudos deveriam investigar se tais resultados são características aplicáveis a todas as famílias de crianças com deficiência. Da mesma forma, a sugestão de Demo (1992) merece investigações. Ele afirma que a união dos pais no mesmo lar com a criança influencia positivamente a relação pai-criança e o bem-estar da criança, pois diminui as chances de falta de supervisão e controle parental, conflitos persistentes entre pais e filhos e violência familiar.

Os resultados do estudo confirmam e expandem aqueles de Lewis e Dessen (1999) em relação a famílias de crianças com desenvolvimentio típico: 1) em lares onde coabitam ambos os genitores, menos de $2 \%$ dos pais compartilham igualmente as tarefas de cuidados da criança com as mães; 2) o papel do homem no cuidado do lar e da criança apresentou-se como tradicional, fazendo-se pouco em relação às atividades de cuidar de suas crianças, sendo esta atividade assumida apenas quando havia impedimento por parte da mãe; 3) os pais relataram gastar o pouco tempo que passavam com seus filhos em atividades prazerosas ("brincar" e "ter lazer junto a elas"), mantendo bom relacionamento com seus filhos, fazendo-Ihes companhia e procurando atender-lhes os pedidos; 4) relataram ser fonte de apoio emocional e financeiro para as mães. Canho et al. (2006) explicam que diferenças de papéis familiares facilitam ao pai um menor envolvimento na educação da criança, mas que se deve valorizar sua importância no processo de reabilitação de crianças com necessidades especiais.

Ainda é necessário considerar que, em determinados contextos, os movimentos sociais não levam a novos papéis parentais: "há evidências de que pais pertencentes a classes sociais mais desfavorecidas detêm uma visão mais tradicional quanto aos papéis que devem desempenhar" (Jablonski, 1999, p.67), que foi o caso da amostra de pais deste estudo. De fato, o quadro apresentado é de poucas ações concretas na diminuição da sobrecarga feminina dentro do lar, sendo o pai um ajudante das tarefas domésticas e de criação dos filhos, como se pode observar em seus relatos, em consonância com os dados salientados por Jablonski (1999). O autor atribui um descompasso entre as fortes influências socializadoras de atitudes igualitárias e os comportamentos masculinos.

Este estudo mostrou que o tempo que os pais gastam com seus filhos portadores de deficiência pode ser considerado significativo: sete entre 11 pais gastavam mais de seis horas diárias com eles. Contudo, futuros estudos deveriam avaliar o quanto esse tempo realmente é despendido com atenção, brincadeiras, cuidados, carinho e estimulação a essas crianças, pois parece que os pais consideravam o tempo em que estavam próximos às crianças realizando outras tarefas como tempo de dedicação a elas.

Entre as contribuições que Engle e Breaux (1998) destacaram que os homens podem fazer aos filhos, observaram-se algumas nos pais deste estudo: passar parte do seu tempo com a criança, tomar a responsabilidade econômica pela criança e reduzir as chances 
de criar um filho fora de uma parceria com a mãe da criança. Porém, Omote (1996) aponta outros fatores a serem considerados especificamente em famílias de indivíduos especiais: o dever de ser envolvido na compreensão das dificuldades e limitações do deficiente, algo que não ocorreu entre muitos pais deste estudo, visto que não estabeleciam contato com profissionais ou com outros pais de crianças com deficiência. É, então, necessário criar vínculos entre pai e profissionais, instituições e famílias de portadores de deficiência mental como meio de adquirir informações relevantes na educação e cuidado de seu filho e estimulá-los a buscar esse vínculo.

Os resultados obtidos sobre lazer com essa amostra de pais parecem confirmar o que Prado (2004) salientou em sua reportagem: a grande maioria dos desempregados (86\% dos pesquisados) eliminava primeiramente o lazer (ir ao cinema, futebol, viagens ou restaurantes) quando precisava conter gastos. Embora no estudo aqui descrito apenas dois pais estivessem desempregados, verificou-se que apenas três famílias (4, 7 e 12) se engajaram em atividades de lazer que envolviam gastos (viagens ou restaurantes).

\section{Considerações Finais}

Uma limitação do estudo diz respeito à quantidade de pais. Para uma caracterização é um número bastante reduzido, porém representa quase a porcentagem total de pais, de acordo com os critérios de seleção pré-estabelecidos, nas cidades onde o estudo ocorreu. Outro fator que há de se considerar é a adequação dos instrumentos a estes pais. Deles, apenas o Inventário HOME possui validação para a população brasileira. PSOC e FES foram de difícil entendimento para pais de baixo nível escolar. Uma vez que há poucos estudos sobre pais (homens) de crianças com deficiência mental, sugere-se a necessidade de construir instrumentos mais apropriados para brasileiros de diferentes níveis educacionais e socioeconômicos desta população especial, para que se possa fazer sua representação mais fiel.

Embora as escalas sejam as mais utilizadas na literatura, deve-se ressaltar a não utilização de apenas um instrumento para avaliar construtos tão complexos como stress, empoderamento, autoestima, ambiente domiciliar, entre outros. Novos estudos deverão aprofundar o conhecimento sobre esses construtos e a sua relação com a paternidade de crianças com deficiência mental. Também foi possível perceber, na avaliação dos pais com estes instrumentos, a necessidade de aprovação social, destacada pelo alto índice de respostas que retratam pais com autoestima elevada, baixo nível de stress e nível alto de empoderamento. $O$ esperado seria que pais empoderados não oferecessem um ambiente domiciliar pobre em estimulação e apoio à criança, pois, se obtêm acesso a conhecimentos, habilidades e recursos que os capacitam a ganhar controle positivo de suas vidas, bem como melhorar a qualidade de seus estilos de vida, deveriam se comprometer mais com a disponibilização de matérias de aprendizagem, estimular o desenvolvimento da linguagem, envolver-se diretamente com a aprendizagem da criança e encorajar a aquisição de habilidades e conhecimento, entre outros. A necessidade de aprovação social, em consonância com a necessidade de rever quanto tempo o pai gasta com seu filho (revertido em atenção, brincadeiras, cuidados, carinho e estimulação) sugere que uma melhor caracterização seria obtida com medidas de observação das interações pai-criança.

Futuros estudos poderiam, ainda, ampliar a caracterização desta população, com pais de crianças, adolescentes e adultos de diferentes idades e de outros tipos de escolas, até mesmo desvinculados de instituições. Também seria plausível, diante da colocação dos pais de que se consideravam iguais aos pais de crianças com desenvolvimento típico, que fossem realizados estudos considerando a introdução de um grupo controle. E, por último, a população de outras regiões do Brasil também deve ser investigada, a fim de se refinar o objetivo aqui almejado.

\section{Referências}

Andrews, A. B., Luckey, l., Bolden, E., Whiting-Fickling, J., \& Lind, K. A. (2004). Public perceptions about father involvement. Journal of Family Issues, 25 (5), 603- 633.

Bailey Jr., D. B., Blasco, P. M., \& Simeonsson, R. J. (1992). Needs expressed by mothers and fathers of young children with disabilities. American Journal on Mental Retardation, 97 (1), 1-10.

Baruffi, A. M. Z. (2000). Família e socialização: um estudo das implicações da situação de presença/ausência paterna, São Paulo. Tese de doutorado não-publicada, Universidade de São Paulo.

Caldwell, B. M., \& Bradley, R. H. (2001). HOME Inventory Administration Manual. Little Rock: University of Arkansas for Medical Sciences. 
Canho, P. G. M., Neme, C. M. B, \& Yamada, M. O. (2006). A vivência do pai no processo de reabilitação da criança com deficiência auditiva. Estudos de Psicologia (Campinas), 23 (3), 261-269.

Caruso, M. (2002). Pais que são mães. [Edição Especial: dia dos Pais] Isto é São Paulo, 1714, 14-18.

Carvalho, M. L. M. (2003). Participação dos pais no nascimento em maternidade pública: Dificuldades institucionais e motivações dos casais. Cadernos de Saúde Pública, 19 (2), 389-398.

Cubero, R., \& Moreno, M. C. (1995). Relações sociais nos anos escolares: família, escola, companheiros. In C. Coll, J. Palácios \& A. Marchesi (Orgs.), Desenvolvimento psicológico e educação: psicologia evolutiva (pp.250-260). Porto Alegre: Artes Médicas.

Demo, D. H. (1992). Parent-child relations: assessing recent changes. Journal of Marriage and the Family, 54 (1), 104-117.

Dessen, M. A. (1985). Considerações sobre variáveis envolvidas na interação pais-criança. Psicologia, Teoriae Pesquisa, 1 (3), 215-226

Dessen, M. A. (2002a). Guia geral de transcrição dos dados de entrevista. Manuscrito não-publicado, Laboratório de Desenvolvimento Familiar, Universidade de Brasília.

Dessen, M. A. (2002b). Questionário de caracterização do sistema familiar. Manuscrito não-publicado, Laboratório de Desenvolvimento Familiar, Universidade de Brasília.

Dessen, M. A., \& Braz, M. P. (2000). Rede social de apoio durante transições familiares decorrentes do nascimento de filhos. Psicologia: Teoria e Pesquisa, 16 (3), 221-231.

Dessen, M. A., \& Lewis, C. (1998). Como estudar a "família" e o "pai"? Paidéia: Cadernos de Psicologia e Educação, 8 (14/15), 105-121.

Engle, P. L., \& Breaux, C. (1998). Father's involvement with children: perspectives from developing countries. Social Policy Report: Society for Research in Child Development, 12 (1), 1-24

Friedrich, W. N., Greenberg, M. T., \& Crnic, K. (1983). A short-form of the questionnaire on resources and stress. American Journal of Mental Deficiency, 88 (1), 41-48.

Glat, R. (1996). O papel da família na integração do portador de deficiência. Revista Brasileira deEducação Especial,2 (4), $111-118$

Gois, A. (2002). Censo aponta aumento no número de pais solteiros. Folha de São Paulo, Caderno Folha Ribeirão, C10.

Guille, L. (2004). Men who batter and their children: an integrated review. Agression and Violent Behavior, 9 (2), 129-163.

Jablonski, B. (1999). Identidade masculina e o exercício da paternidade: de onde viemos e para onde vamos. In T. Féres-Carneiro (Org.), Casal e familia: entre a tradição e a transfomação (pp.55-69). Rio de Janeiro: Nau.

Johnston, C., \& Mash, E. J. (1989). A measure of parent satisfaction and efficacy. Journal of Clinical Child Psychology, 18 (2), 167-175.
Kane, P., \& Garber, J. (2004). The relations among depression in fathers, children's psychopathology, and father-child conflict: a meta-analysis. Clinical Psychology Review, 24 (3), 339-360.

Kassotaki, K. M. (2002). Understanding fatherhood in Greece: father's involvement in child care. Psicologia: Teoria e Pesquisa, 16 (3), 213-219.

Koren, P. E., De Chillo, N., \& Friesen, B. (1992). Measuring empowerment in families whose children have emotional disabilities: a brief questionnaire. Rehabilitation Psychology, 37 (4), 305-321.

Lamb, M. E. (1997). Fathers and child development: An introductory overwiew and guide. In M. E. Lamb (Org.), The role of the father in child development (pp.1-18). New York: Wiley.

Lamb, M. E., \& Billings, L. A. L. (1997). Fathers of children with especial needs. In M. E. Lamb (Org.), The role of the father in child development (pp.179-190). New York: Wiley.

Levandowski, D. C., \& Piccinini, C. A. (2002). A interação pai-bebê entre pais adolescentes e adultos. Psicologia: Reflexão e Crítica, 15 (2), 413-424.

Lewis, C., \& Dessen, M. A. (1999). O pai no contexto familiar. Psicologia: Teoria e Pesquisa, 15 (1), 09-16.

Martins, M. F. D., Costa, J. S. D., Saforcada, E. T., \& Cunha, M. D. C. (2004). Qualidade do ambiente e fatores associados: um estudo em crianças de Pelotas, Rio Grande do Sul, Brasil. Cadernos de Saúde Pública, 20 (3), 710-718.

Omote, S. (1996). Conclusões do grupo de trabalho (GT3): a família do deficiente. In C. Goyos, M. A. Almeida \& D. Souza (Orgs.), Temas em educação especial 3 (pp.516-525). São Carlos: UFSCar.

Omote, S. (1998). Famílias de deficientes: estudos relatados em dissertações e teses. In M. C. Marquezine, M. A. Almeida, E. D. O. Tanaka, N. N. R. Mori \& E. M. Shimazaki (Orgs.), Perspectivas multidisciplinares em educação especial (pp.125-129). Londrina: UEL.

Pereira-Silva, N. L., \& Dessen, M. A. (2003). Crianças com síndrome de Down e suas interações familiares. Psicologia: Reflexão e Crítica, 16 (3), 503-514.

Prado, M. (2004). Desempregados de SP andam a pé, não viajam nem compram roupa. Folha de São Paulo, Caderno de Dinheiro, B4.

Sigolo, S. R. R. L. (2004). Favorecendo o desenvolvimento infantil: ênfase nas trocas interativas no contexto familiar. In E. G. Mendes, M. A. Almeida \& L. C. A. Williams (Orgs.), Temasemeducaçãoespecial:avanços recentes (pp.189-195). São Carlos: EDUFSCar.

Williams, L. C. A., \& Aiello, A. L. R. (2004). Empoderamento de famílias: o que vem a ser e como medir. In E. G. Mendes, M. A. Almeida \& L. C. A. Williams (Orgs.), Temas em educação especial: avanços recentes (pp.197-202). São Carlos: EDUFSCar.

Recebido em: 4/5/2007

Versão final reapresentada em: 1/10/2007

Aprovado em: 13/12/2007 